of his two volumes on comparative visual mechanisms. His contacts with animal ophthalmology have covered a wide field and current interpretations of ocular structure and theories of visual function in man and representative animals are here reviewed in the light of his own experiences. The result is a most interesting and readable work, concluding with a section, invaluable to the ophthalmologist who wishes to explore this field, on practical methods of examination of animal eyes, and an excellently illustrated chapter on animal fundi.

H.E.H.

\section{DIABETES AND ITS TREATMENT}

By Joseph H. Baruch, M.D., F.A.C.P. Pp. xviii +326 , with 73 illustrations. New York and London: Geoffrey Cumberlege (Oxford Medical Publications). 1949. £2 ros.

This book is obviously the work of a physician of wisdom and humanity, who has made a long study of diabetic patients and their problems. I enjoyed reading it, particularly for the clear description of many small practical problems, the solution of which adds so much to the day-to-day comfort of the diabetic; and for the author's personal views on debatable questions.

I cannot agree, however, that it is an ideal book for the 'general medical man' in Great Britain. One-third of the book consists of details of $31_{5}$ diets. Different diets are provided for men, women and children of all ages and sizes, but no mention is made of varying the distribution and size of meals when using different types of insulin. These diets would not be suitable for English patients without modification, and the whole system appears cumbrous. The English (or American) at times lacks precision, particularly in such sentences as 'thus it is that a patient may have disturbances of visual acuity due to the effects of excessive blood sugar and altered media on the nerve and muscle structures of the eye.' The space devoted to different subjects often bears little relation to their importance in practice. I have yet to meet an English houseman who could be trusted, or who would even attempt, to estimate the blood plasma $\mathrm{CO}_{2}$, blood sugar, blood NPN or urea nitrogen, blood chloride, cholesterol, blood acetone, urine sugar quantitative, leucocyte count and differential count of a patient in diabetic coma; nor do I believe that these estimations are generally necessary for the successful treatment of such a case. Insulin dosages are often prescribed in multiples of 5, whereas with Englihs syringes marks practically always correspond to multiples of 2,4 or 8 .

This book cannot be recommended to the student or practitioner in search of simple instructions for the treatment of diabetic patients. It will, however, prove of considerable interest to the postgraduate, who already has a fair practical experience of the treatment of diabetes and can afford 50s. for a book of moderate length.

\section{DISEASES OF THE NERVOUS SYSTEM}

By F. M. R. Walshe, O.B.E., F.R.S., F.R.C.P. 6th Edition. Pp. xvi +359 , with 60 illustrations. Edinburgh: E. \& S. Livingstone. r949. r7s. 6 d.

The success and popularity of Dr. Walshe's book is indicated by the fact that it has been re-edited or reprinted ten times in as many years, and has been distinguished by French and Spanish editions as well.

The present edition has added information and instruction on the pathology and treatment of neurosyphilis with special reference to penicillin; the chapters on poliomyelitis and intracranial abscess have been expanded, whilst advances which have proved their worth, such as the use of tridione in epilepsy, have been included in different parts of the book. The essential arrangement of the work is unaltered. Although it is increased in size, the reader will find his journey through its 360 pages pleasant and profitable, and if he appreciates plain but beautifully written English as well, he will feel refreshed and ready for more at the end of it.

Few writers of medical textbooks think of the general practitioner as they piece together their vast tomes. Dr. Walshe has never lost sight of them, so that they above all will appreciate the author's direct common-sense approach to his subject and his ruthless ostracism of eponymous signs and fancy names 'which hang like dust upon the brain, or dry like raindrops off the stones.'

The author is quite right in adopting a conservative attitude to the introduction of new matter, but it is felt that some of our neurosurgeons and particularly Professor Olivecrona of Stockholm would be surprised to learn that cortical angiomas are inoperable (p. 133). It is a pity, too, that more information about penicillin therapy in neurosyphilis should not have been given. Surely some assessment of its real worth might have been forthcoming, bearing in mind the large-scale trials which have already been undertaken, especially in the United States.

Intended primarily for the practitioner and general physician, those who feel they are well versed in the principles and practice of neurology will gain much from this fine work. Even if they fail to add new knowledge to their store, which is unlikely, they will certainly cull more wisdom and the art of thinking more clearly and more precisely in the pursuit of their speciality. D.S.L.

\section{RELAXATION AND EXERCISE FOR NATURAL CHILDBIRTH}

By Helen Heardman. Pp. 32, with 22 figures. Edinburgh: E. \& S. Livingstone. 1950. $9 \mathrm{~d}$.

A useful booklet on the subject of exercises before and after childbirth. Written in plain, simple language, easily understood by any mother. Can be recommended. 